\title{
Carbon fixation and energy metabolisms of a subseafloor olivine biofilm
}

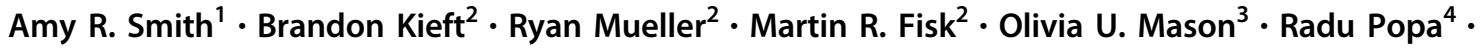 \\ Frederick S. Colwell ${ }^{2}$
}

Received: 6 August 2018 / Revised: 15 February 2019 / Accepted: 28 February 2019 / Published online: 12 March 2019

(c) International Society for Microbial Ecology 2019

\begin{abstract}
Earth's largest aquifer ecosystem resides in igneous oceanic crust, where chemosynthesis and water-rock reactions provide the carbon and energy that support an active deep biosphere. The Calvin Cycle is the predominant carbon fixation pathway in cool, oxic, crust; however, the energy and carbon metabolisms in the deep thermal basaltic aquifer are poorly understood. Anaerobic carbon fixation pathways such as the Wood-Ljungdahl pathway, which uses hydrogen $\left(\mathrm{H}_{2}\right)$ and $\mathrm{CO}_{2}$, may be common in thermal aquifers since water-rock reactions can produce $\mathrm{H}_{2}$ in hydrothermal environments and bicarbonate is abundant in seawater. To test this, we reconstructed the metabolisms of eleven bacterial and archaeal metagenome-assembled genomes from an olivine biofilm obtained from a Juan de Fuca Ridge basaltic aquifer. We found that the dominant carbon fixation pathway was the Wood-Ljungdahl pathway, which was present in seven of the eight bacterial genomes. Anaerobic respiration appears to be driven by sulfate reduction, and one bacterial genome contained a complete nitrogen fixation pathway. This study reveals the potential pathways for carbon and energy flux in the deep anoxic thermal aquifer ecosystem, and suggests that ancient $\mathrm{H}_{2}$-based chemolithoautotrophy, which once dominated Earth's early biosphere, may thus remain one of the dominant metabolisms in the suboceanic aquifer today.
\end{abstract}

\section{Introduction}

The igneous suboceanic aquifer contains a globallydistributed chemosynthetic ecosystem supported largely by water-rock reactions [1-4]. The Calvin Cycle is the dominant carbon fixation pathway in the upper oceanic crust where cool, oxygenated seawater circulates through exposed crustal rocks [5]. However, the aquifer

Supplementary information The online version of this article (https:// doi.org/10.1038/s41396-019-0385-0) contains supplementary material, which is available to authorized users.

Amy R. Smith

asmith@whoi.edu

1 Woods Hole Oceanographic Institution, Marine Chemistry and Geochemistry, Woods Hole Oceanographic Institution, 266 Woods Hole Road, MS \#51, Woods Hole, MA 02543, USA

2 Oregon State University, Corvallis, OR 97330, USA

3 Florida State University, Tallahassee, FL 32306, USA

4 University of Southern California, Los Angeles, CA 90089, USA extends deeper into a thermal anoxic zone that remains habitable but is more conducive to anaerobic carbon fixation pathways like the Wood-Ljungdahl pathway. The Juan de Fuca Ridge (JdFR) crustal aquifer is one location where this pathway is likely to occur since it underlies thick sediment deposits which limit thermal exchange with the overlying water column [6-8]. This is a deep thermal aquifer ( $>300$ meters below the seafloor; $\sim 64{ }^{\circ} \mathrm{C}$ ) contained within young ( 3.5 mya) basaltic oceanic crust, a prime habitat for a chemosynthetic microbial ecosystem.

The thermodynamic disequilibrium between warm aquifer fluid and reduced, Fe-bearing minerals in the crust (e.g., olivine) can be exploited by microbes for energy under the thermal conditions in which $\mathrm{H}_{2}$ is produced [9, 10]. Molecular hydrogen is an energy-rich electron donor, and may be a driver for microbial chemosynthesis in deep aquifer ecosystems such as the JdFR where oxygen and organic matter are limited and $\mathrm{H}_{2}$ is present [11]. The JdFR aquifer community contains distinct planktonic and sessile communities [12-17], and minerals appear to shape the structure and function of the attached 
community, favoring lineages that contain the WoodLjungdahl pathway $[1,12,18,19]$. This suggests that chemosynthetic $\mathrm{H}_{2}$-based metabolisms are supported by water-rock reactions on Fe-bearing mineral surfaces in thermal anoxic aquifers like the JdFR.

The Wood-Ljungdahl, or reductive acetyl-CoA, pathway is an ancient carbon fixation pathway employed primarily by acetogenic bacteria, archaeal sulfate reducers, or methanogens [20-23], which commonly occupy niches close to the thermodynamic limits of life [24]. In acetogenesis, molecular hydrogen $\left(\mathrm{H}_{2}\right)$ and inorganic carbon $\left(\mathrm{CO}_{2}\right.$ or $\left.\mathrm{HCO}_{3}{ }^{-}\right)$are metabolized by the two branches of the Wood-Ljungdahl pathway (the methyl and the carbonyl branches) to synthesize acetyl-CoA [20,25], a key biomolecular precursor that links multiple carbon and energy metabolic pathways in the cell (e.g., lipid, protein, and carbohydrate metabolism). Methanogens use a different suite of enzymes in the methyl branch, eventually producing methane. The carbonyl branch, also called the acetyl-CoA pathway, is common to both methanogenesis and acetogenesis, and can be reversed with electrons from acetate being donated to sulfate as a terminal acceptor [24].

To explore the role of the Wood-Ljungdahl pathway in the carbon and energy metabolisms of microbes that live on olivine in the deep JdFR suboceanic aquifer, we produced eleven metagenome-assembled genomes (MAGs) from an olivine microbial biofilm that colonized the mineral over 4 years in situ (Fig. 1) [12]. The carbon fixation pathways and energy metabolisms encoded in the MAGs were identified through metabolic pathway reconstruction. We found that the primary carbon and energy pathways were acetogenesis via the WoodLjungdahl pathway and sulfate reduction.

\section{Materials and methods}

\section{Overview of experimental design and study site}

Details of oceanic crust mineral incubation and retrieval were previously reported ([12, 26]; Supplementary Methods). Briefly, olivine forsterite $100\left(\mathrm{Fo}_{100}\right)$ olivine $\left(\mathrm{Mg}_{2} \mathrm{SiO}_{4}\right)$, forsterite $90\left(\mathrm{Fo}_{90}\right)$ olivine $\left[\left(\mathrm{Mg}_{0.9} \mathrm{Fe}_{0.1}\right)_{2} \mathrm{SiO}_{4}\right]$, and other minerals were placed sequentially within chambers of a flow cell that was connected to an osmotic pump. The flow cell was suspended in 3.5-mya basaltic crust at IODP Hole 1301A $\left(47^{\circ} 45.210 \mathrm{~N}, 127^{\circ} 45.833^{\prime} \mathrm{W} ; 2,667 \mathrm{~m}\right.$ water depth) from 2004-2008 between 275 and 287 meters below seafloor (mbsf; Fig. 1a, b) [6, 26]. Seawater entrainment occurred in the borehole during the first 3 years of incubation; [27] however, in the fourth year the aquifer fluid chemistry and temperature changed to that which is more representative of the natural thermal aquifer: $\sim 64^{\circ} \mathrm{C}$ aquifer fluid rich in sulfate $\left(17.6 \mathrm{mmol} \mathrm{kg}^{-1}\right)$, iron $\left(0.8 \mu \mathrm{mol} \mathrm{kg}{ }^{-1}\right)$, and ammonium $\left(111 \mu \mathrm{mol} \mathrm{kg}{ }^{-1}\right)$, with some nitrate $(0.8$ $\left.\mu \mathrm{mol} \mathrm{kg} \mathrm{k}^{-1}\right)$ and a source of hydrogen that could support hydrogenotrophy $\left(\sim 2 \mu \mathrm{M} \mathrm{H}_{2}\right)[11,27,28]$. Organic carbon concentrations in the aquifer are depleted relative seawater [29]. Fluid flow increased over time (along with temperature) to a final flow rate of $200 \mathrm{~mL} / \mathrm{year}$ that persisted for the last year of incubation [27]. Upon recovery of the assembly aboard the ship, the olivine was frozen at $-40^{\circ} \mathrm{C}$ where it remained until extraction.

\section{DNA extraction and sequencing}

All steps for sequencing and metagenome analysis are briefly summarized here; for complete details, see Supplementary Methods. Genomic DNA was extracted from
Fig. 1 Summary of subseafloor olivine colonization study. a) Simplified schematic of IODP Borehole 1301A on the eastern flank of the Juan de Fuca Ridge (well depth 367 mbsf) Modified from $[6,7,26]$. The microbial flow cell containing olivine was suspended in the basaltic basement and exposed to lateral aquifer fluid flow from the basalt. b) Location of Hole $1301 \mathrm{~A}$ on the eastern flank of the Juan de Fuca Ridge at a depth of 2,667 m
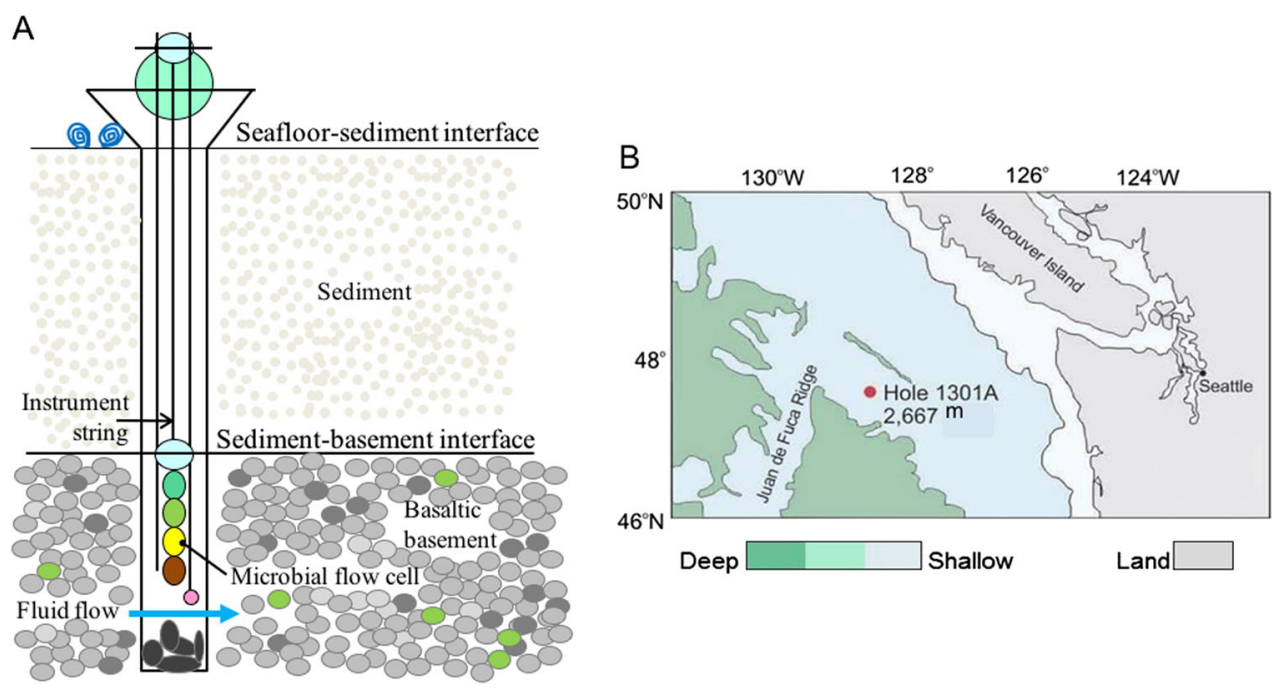


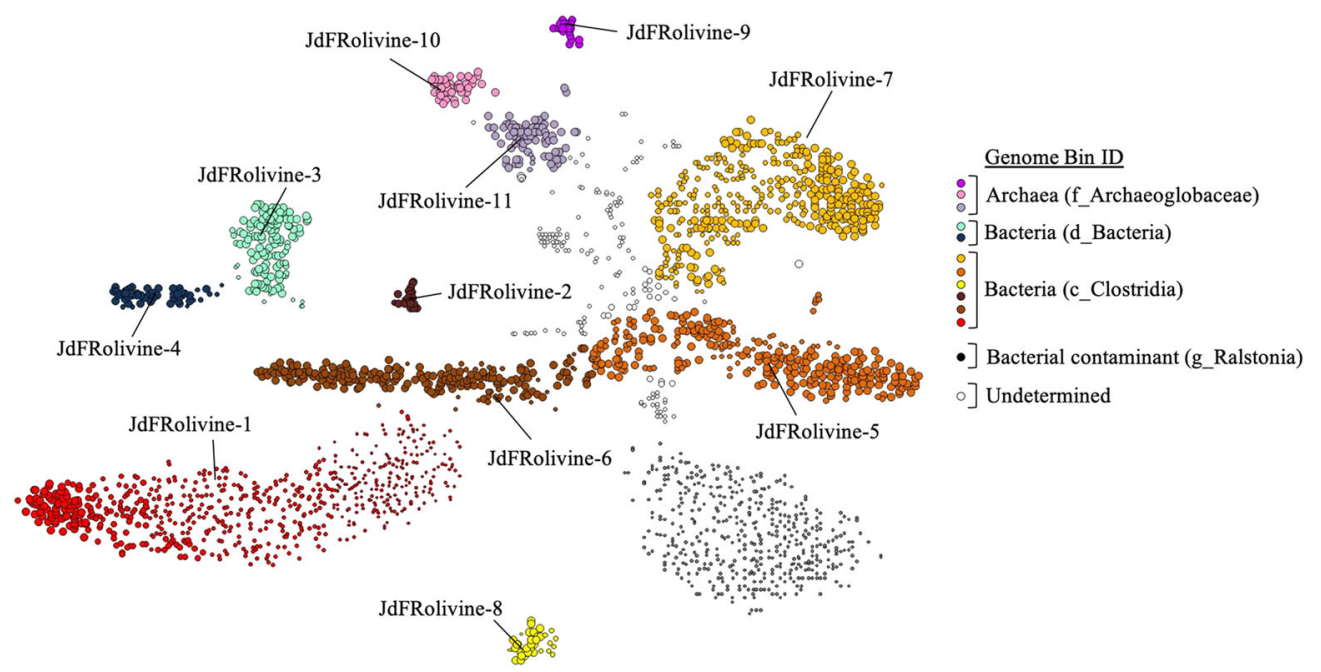

Fig. 2 Clustering of the olivine metagenome contigs using tetranucleotide frequency. Eleven genomic bins were produced from the olivine metagenome; one additional bin was determined to be a contaminant (Supplementary Methods). MAGs 1-8 are Bacteria: orange, red, and yellow-toned circles denoting Firmicutes from the class Clostridia (1,2, and 5-8), blues (3 and 4) are only classified as in the domain Bacteria, and black (not numbered) is a Proteobacterial

$\sim 500 \mathrm{mg}$ olivine sand using a modified protocol for the FastDNA Spin Kit for Soil (MP Biomedicals Catalog \#116560200) and amplified by PCR as described previously $[12,30]$. Genomic DNA (50-70 ng) was pooled from two olivine phases and sequenced at the Marine Biological Laboratory (MBL) in Woods Hole, MA (for more details, see ref. 31). We used an Illumina Hi-Seq1000 for 2x100 bp paired-end sequencing with dedicated-read indexing. Consensus Assessment of Sequence and Variance (CASAVA) 1.8.2 (Illumina) was used to demultiplex sequences at MBL.

\section{Metagenome assembly and binning}

Raw sequence files were concatenated into Read 1 and Read 2 files and then sent through the String Graph Assembler (SGA)'s pre-processing pipeline [32]. Reads with quality scores less than 10 or those less than 50 base pairs were eliminated. Ambiguous bases were base-called and the final read set was output into a quality-controlled, interleaved sequence pair file.

We used the Iterative deBruin Graph Assembler-Uneven Depth (IDBA-UD) metagenome assembler v0.20 [33] and VizBin [34] to assemble and bin sequences, respectively (Supplementary Tables $1 \&$ 2). We used PhyloPythiaS v1.0 [35] to assign taxonomy to contigs in VizBin for manual curation, CheckM v1.0.6 [36] to assess bin completeness and contamination, and PhyloSift v1.0.1 [37] with marker database v4 to verify bin taxonomy (Supplementary Methods, Supplementary Figure $1 \&$ Supplementary Tables $2 \&$ 3). Bins were manually curated based on PhyloPythia laboratory contaminant (genus Ralstonia). White circles could not be determined as belonging to any particular bin and were not analyzed further. MAGs 9-11 (pink and purple tones) are Archaea of the family Archaeoglobaceae (see Supplementary Table 3 for marker gene summary and Supplementary Table 1 for complete bin phylogeny summary). Each circle represents a contig from the metagenome assembly

taxonomy and contigs that could not be binned with confidence were marked "undetermined" (Fig. 2). These contigs were manually searched to confirm the absence of genes relevant to the carbon fixation and energy metabolisms described here. We finally named each bin according to the location and mineral it was produced from (JdFRolivine) and the bin number. Details of contamination removal (black circles; Fig. 2) are provided in Supplementary Methods.

\section{Comparative genome analysis}

We used programs in The U.S. Department of Energy Systems Biology Knowledgebase (KBase) to determine relatedness of MAGs to genomes from ref. [15] and other publicly available genomes (Supplementary Table 4). We used Fast Whole-Genome Similarity (FastANI) KBase v.0.0.12 to determine the similarity between genomes, Rapid Annotations using Subsystems Technology (RAST) v.0.0.12 to annotate proteins, and Species TreeBuilder v.2.1.10 to construct phylogenetic trees based on highly conserved concatenated protein sequences (Fig. 3). See Supplementary Methods for more detail.

\section{Protein prediction and metabolic reconstruction}

Prodigal v2.6.0 [38] was used to predict proteins and determine open reading frames in the kmer 65 assembly of the olivine metagenome obtained using IDBA-UD. Predicted genes from Prodigal were input into DIAMOND v0.6.13.48 using blastp against the refseq database [39] to 


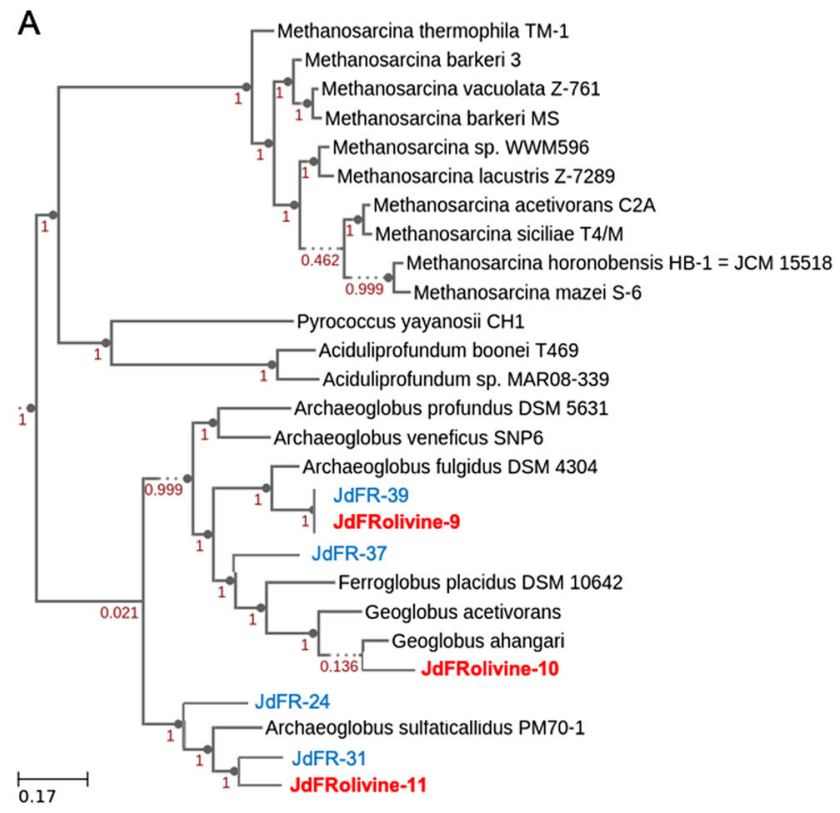

B

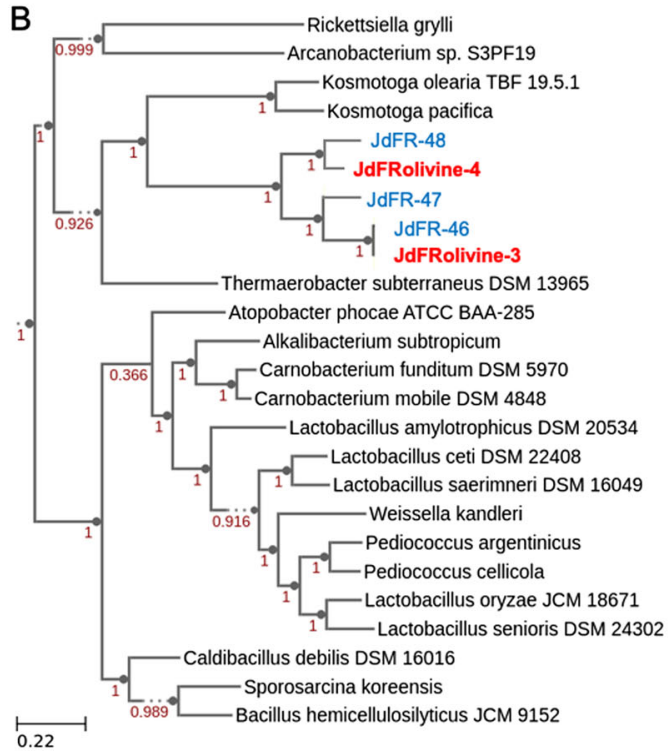

Fig. 3 Maximum likelihood phylogeny of olivine MAGs using 49 highly conserved protein domains. a) Archaeoglobaceae. b) Bacteria. c) Clostridia. Select closely-related fluid-derived MAGs from JdFR are

assign function to proteins. Clusters of Orthologous Proteins (COGs) were produced from the protein file using Reverse PSI-Blast (rpsblast; National Center for Biotechnology Information, or NCBI) and were used to search for gene candidates not identified by KEGG (i.e., formate dehydrogenase). We used BlastKOALA v.2.1 (Basic Local Alignment Search Tool KEGG Orthology and Links Annotation) from the Kyoto Encyclopedia of Genes and Genomes (KEGG) for metabolic reconstruction [40].

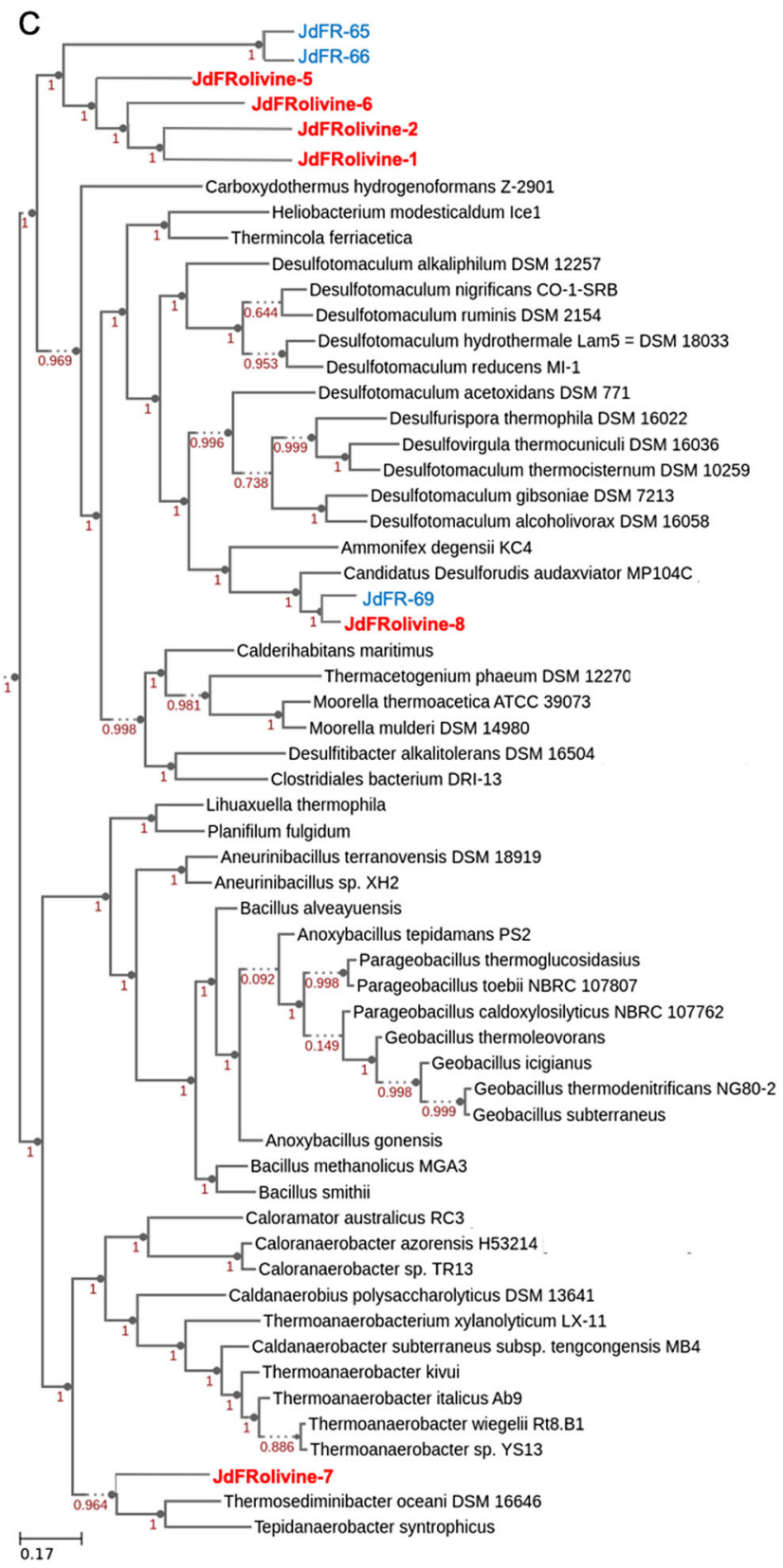

represented with blue text [52]. Red text are MAGs JdFRolivine-1-11 from Fig. 2

\section{Identification of specific genes}

Putative formate dehydrogenase genes were identified for those genomes missing an annotated $f d h A$ gene to complete the Wood-Ljungdahl pathway (Supplementary Table 5), and the Iterative Threading ASSEmbly Refinement v.5.1 (I-TASSER; https://zhanglab.ccmb.med.umich. edu/I-TASSER/) was used to determine structural relatedness of identified protein sequences (Supplementary 


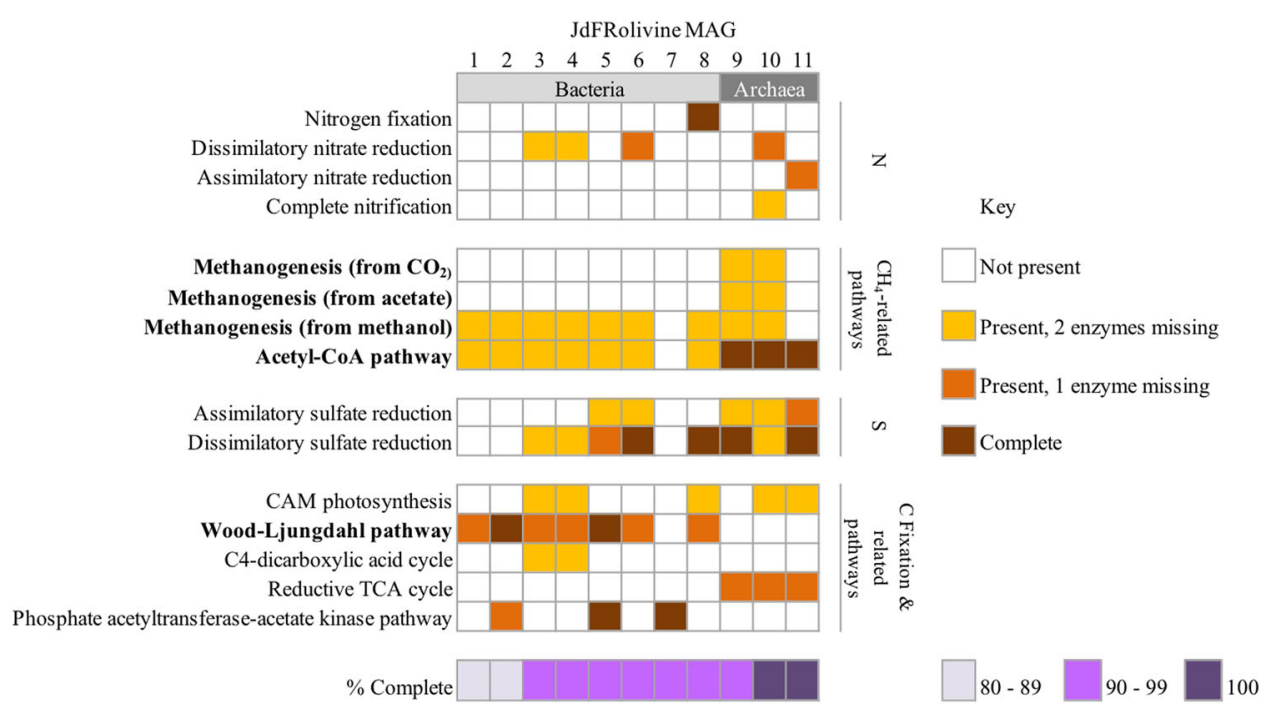

Fig. 4 Summary of carbon fixation, methane, nitrogen, and sulfur cycling pathways present in olivine MAGs as determined from the KEGG Pathway Module. Colored boxes indicate the presence of genes for each listed pathway. Any pathways not listed were absent from genome bins, including the Calvin cycle and other carbon fixation

Table 6). Each putative $f d h A$ protein sequence was also aligned with the acetogen Moorella thermoacetica's fdhA protein sequence using NCBI's BLASTp. Hydrogenases, ferredoxins, and cytochromes were pulled from KEGG annotations to compare the potential for redox and electron transfer mechanisms across genomes (gene descriptions are provided in Supplementary Tables 7-9).

\section{Results}

\section{Metagenome assembly and genome binning}

Eleven high-quality ( $>90 \%, n=9)$, or medium-quality $(>81.19 \%, n=2)$ draft MAGs were obtained in this study (Figs 2-4; Supplementary Figure 1) [41]. The metagenome contained 84 million reads with an average length of 108 bases post-quality filtering. Total assembly size was 30,811,948 bases (Supplementary Table 2), with an N50 of 19,191. Minimal contamination or strain heterogeneity was observed in each genomic bin (Supplementary Figure 1), likely a result of clear separation between the twelve discrete clusters of contigs based on tetranucleotide frequency (Fig. 2).

\section{Carbon fixation pathways}

We found that the majority of organisms from this deep thermal olivine biofilm community possessed complete or near-complete carbon fixation pathways (Fig. 4) based on the current KEGG Carbon Fixation Pathway Modules. At least two Clostridia (JdFRolivine-2 and 5) from the community pathways, and other nitrogen cycling pathways. Carbon and energy metabolisms and related pathways are separated by color and each metabolism listed on the right. Completeness for each genome is listed at the bottom of the figure

possess the full suite of enzymes in both branches of the Wood-Ljungdahl pathway. Another five bacterial MAGs (JdFRolivine-1, 3, 4, 6, and 8) contain near-complete WoodLjungdahl pathways (Figs 3, 4a, b). The phosphate acetyltransferase-acetate kinase pathway, which allows the conversion of acetyl-CoA to acetate, is a critical energy conservation step in the Wood-Ljungdahl pathway. It was only present in two Bacterial genomes, only one of which contains the complete Wood-Ljungdahl pathway (Fig. 4). This suggests that the Wood-Ljungdahl pathway may be used primarily for carbon fixation rather than energy generation in this community. Notably, all Archaeal MAGs (JdFRolivine-9, 10, and 11) also contained the complete pathway for carbon fixation via the acetyl-CoA pathway (Fig. 4), which allows for the conversion of $\mathrm{CO}_{2}$ into acetyl-CoA. Two of these MAGs have genes coding for acetate reduction coupled to sulfate reduction (Fig. 4) [42]. Some genes that code for enzymes involved in other carbon fixation pathways were present; however, none of the MAGs contained complete pathways, supporting the notion that they do not play a role in carbon fixation in this system (Fig. 4).

Although nearly all of the bacterial MAGs encoded significant portions of the Wood-Ljungdahl pathway, most of these (five of seven MAGs) were missing annotations for one of the two genes commonly found in genomes of terrestrial acetogens (Fig. 5a, b). JdFRolivine-3 and 4 ('Bacteria') are missing the enzyme methylene-tetrahydrofolate reductase (metVF), and JdFRolivine-1, 6, and 8 are missing the typical formate dehydrogenase $(f d h A B)$. However, we identified putative $f d h A$ genes in these genomes whose predicted function includes $f d h A$ (Supplementary Tables 5 


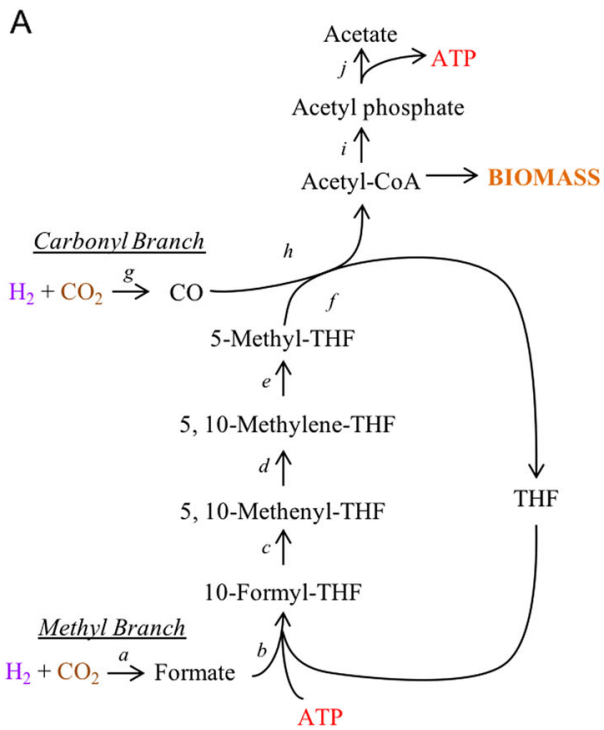

B

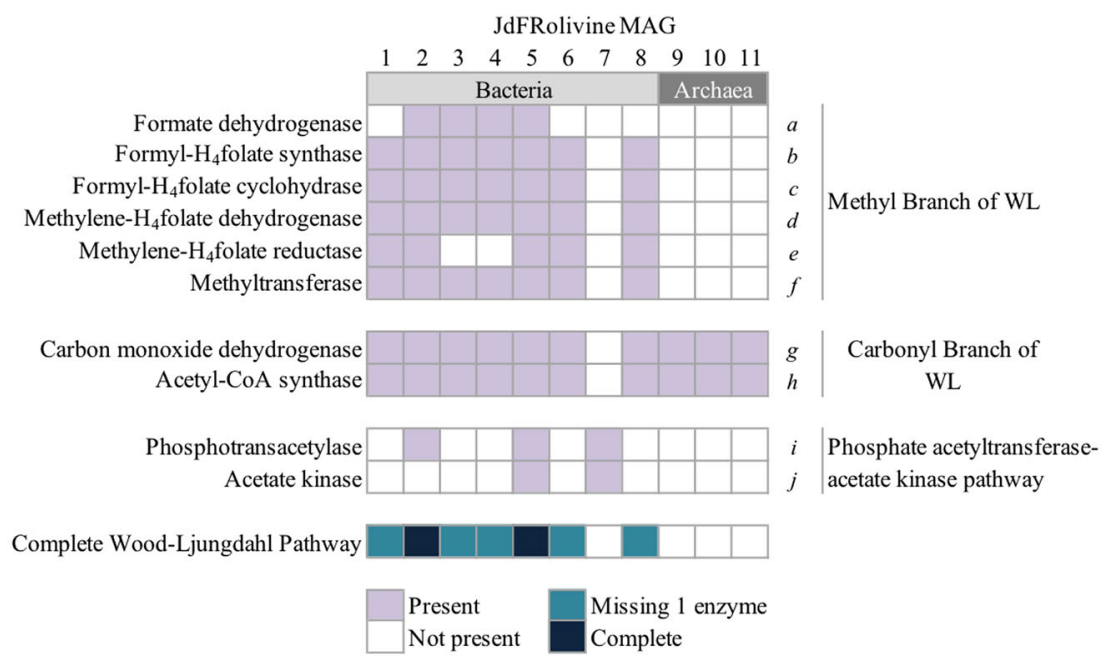

C

JdFRolivine MAG

Formate dehydrogenase, alpha subunit $f d h A$ Formate dehydrogenase D protein, assembly factor $f d h D$

Formate dehydrogenase maturation protein, $f d h E$

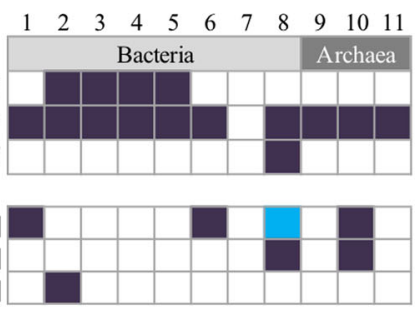
Formate dehydrogenase, iron-sulfur subunit $f d o H$ [EC:1.2.1.2] Formate dehydrogenase, beta subunit E1.2.1.2B2 [EC:1.2.1.2]

$p f l X$, putative pyruvate formate lyase activating enzyme [EC:1.97.1.4] $p f l A$, pyruvate formate lyase activating enzyme [EC:1.97.1.4] Formate C-acetyltransferase [EC:2.3.1.54]

Fig. 5 Wood-Ljungdahl pathway summary for olivine MAGs. a Wood-Ljungdahl pathway with enzymes $(a-j)$ linked to b summary of WL pathway enzymes in each MAG. c Presence of potential

\& 6). These MAGs also may potentially use alternate routes of formate production, whether by producing it outside of the Wood-Ljungdahl pathway or through use of analogous subunits from other formate dehydrogenases (Fig. 5c). We alternatives to formate dehydrogenase in JdFRolivine genomes (enzyme commission numbers are in brackets). Formate Cacetyltransferase is also known as pyruvate formate lyase

also identified acetyl-CoA synthase (acs) gene clusters in each of the MAGs containing the Wood-Ljungdahl pathway, suggesting these organisms are true acetogens and use the Wood-Ljungdahl pathway to generate acetyl-CoA by 
reducing $\mathrm{CO}_{2}, \mathrm{CO}$, and/or formate (Supplementary Figure 2).

\section{Nitrogen, sulfur, and iron cycling}

The JdFRolivine- 8 MAG, identified as a Firmicute from the Peptococcaceae family, has both the complete pathway for nitrogen fixation and dissimilatory sulfate reduction to $\mathrm{H}_{2} \mathrm{~S}$ (Fig. 4). Three other Archaeoglobaceae and Firmicute MAGs also contained the dissimilatory sulfate reduction pathway (Supplementary Table 1; Fig. 4); however, no complete sulfate importers were identified. Although there were no complete pathways or enzymes for iron reduction, JdFRolivine-10 is a close relative of the iron reducer Geoglobus (Fig. 3) [43]. This MAG has genes to produce some of the proteins in the iron reduction complex of Geoglobus acetivorans, but not omc genes which are required for dissimilatory iron reduction. No $c y c 2$ genes used in iron oxidation were found [44], and no complete pathways for iron-dependent dissimilatory nitrate reduction were present. No other pathways were present for nitrogen, sulfur, or iron cycling, suggesting nitrogen fixation, sulfate reduction, and iron reduction are the key energy respiratory pathways occurring in this community.

\section{Hydrogenases and electron transfer agents}

The presence and abundance of different hydrogenases and other Electron Transfer Agents (ETAs) can be an indicator of modes of energy metabolism, such as hydrogenotrophy. All characterized MAGs contained hydrogenase genes (Fig. 6a; Supplementary Table 4), and most contained the hypABCDEF and hyaABD genes that encode for [NiFe] hydrogenases. JdFRolivine-3 and 4 had identical hydrogenase genes. Two Clostridia (JdFRolivine-5 and 8) were more similar in terms of presence and copies of hydrogenase genes, but JdFRolivine-8 had more gene copies of the hya hydrogenase, and JdFRolivine-5 contained a unique gene that was not present in any other genome, hyaC, the [NiFe] hydrogenase 1B-type cytochrome subunit. These two MAGs are also the only two that contained an ech, or 'energy conserving', hydrogenase gene, again showing the similarity between these two MAGs in terms of hydrogenase genes. MAGs that belong to different phylogenetic groups such as JdFRolivine-7 (Clostridia), JdFRolivine-9 (Archaeoglobaceae), and JdFRolivine-2 (Clostridiaceae) had distinct varieties of hydrogenases not found in other MAGs. Archaeal genomes also had different hydrogenase genes than bacterial genomes, except for hypABCDEF and hyaABD. Archaeal genomes were the only ones that contained the $\mathrm{F}_{420}$-reducing hydrogenase $h n n C D$ genes.

Ferredoxin genes were variable across the metagenome (Fig. 6b; Supplementary Table 5); however, most MAGs
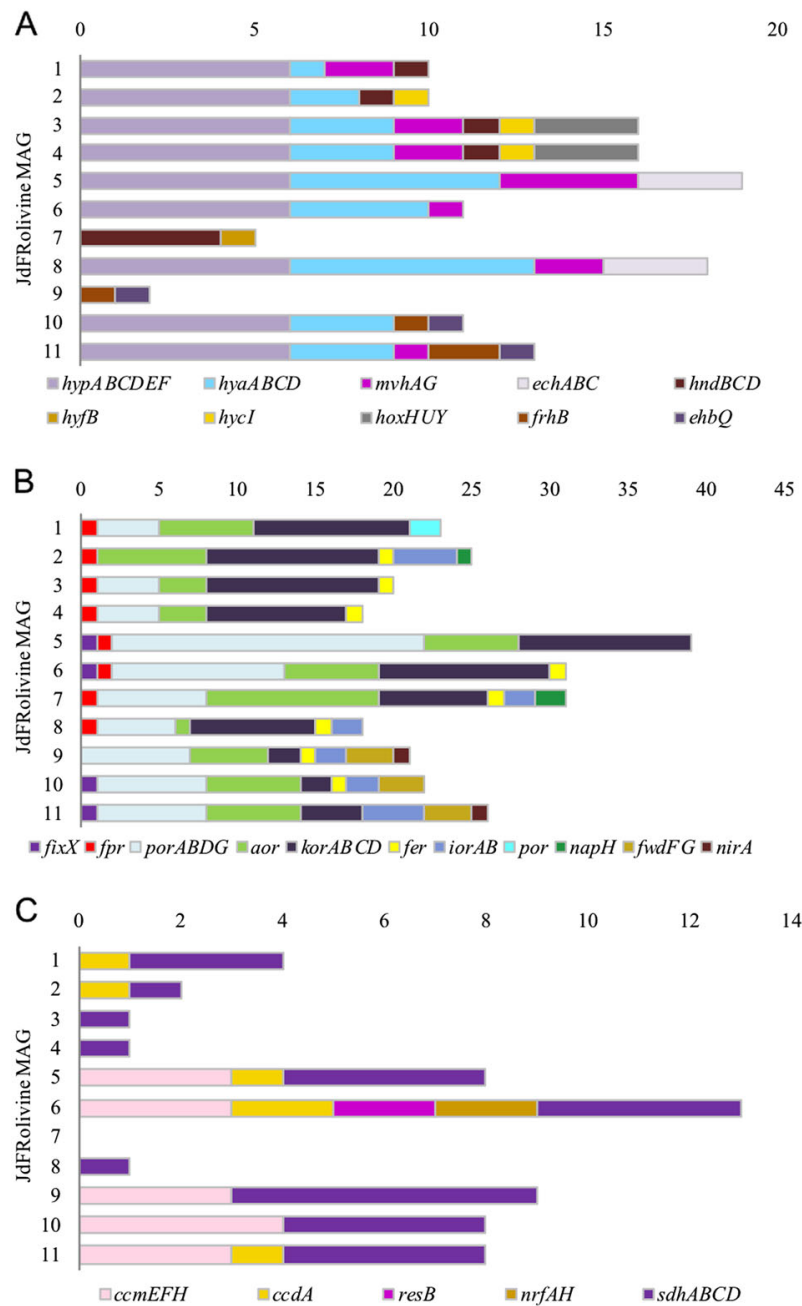

Fig. 6 Hydrogenases and Electron Transfer Agents (ETAs) present in KEGG-annotated olivine MAGs. The number of copies of each gene in a genome is indicated on the X-axis. MAG ID numbers are listed on the $y$-axis. a Hydrogenases and related genes that play key roles in hydrogenase function. b Ferredoxin-related genes found in olivine MAGs. c Cytochromes and other ETAs. See Supplementary Tables $7-$ 9 for gene descriptions

had several ferredoxin genes in common, with some ferredoxins unique to either individual genomes or particular lineages. All MAGs contained the aor and $k o r A B$ ferredoxins, and most contained porABDG, the pyruvate:ferredoxin oxidoreductase, which catalyzes the reversible conversion of pyruvate to acetyl-CoA. Only bacterial MAGs (JdFRolivine-2 through 9) contained the fpr ferredoxin, which is generally used to reduce NADP + for anabolism. JdFRolivine- 6 contained the greatest number of copies of ferredoxin genes, mainly due to extra copies of the por ferredoxin. JdFRolivine-1, 5, and 11 which all belong to different lineages did not contain the fer gene for ferredoxin.

Cytochromes and other ETAs (Fig. 6c; Supplementary Table 6) were highly variable most containing at least $s d h A$. 
JdFRolivine-6 contained a unique ETA, $n r f H A$, which reduces nitrite to ammonium during respiration [45]. JdFRolivine-7 contained no cytochromes or other ETAs, and JdFRolivine- 3 , 4, and 8 only contained one cytochrome gene, $s d h A$.

\section{Heterotrophy in JdFRolivine MAGs}

Other than the potential for some MAGs to utilize simple carbohydrates and a few specific types of amino acids, there is little evidence for the import and degradation of organic compounds for carbon and energy in this community. Most MAGs contained just one or two amino acid transporters, only three MAGs (JdFRolivine-3, 4, and 7) contained carbohydrate importers, and three had complete glycolysis pathways (JdFRolivine-2, 7, and 8). No lipid importers were identified in this study.

\section{Discussion}

\section{Phylogeny of lineages from the olivine biofilm and the deep JdFR aquifer}

We obtained eleven draft genomes that represent undefined Bacteria, Clostridia, and Archaeoglobaceae (Supplementary Table 1), many of which are present only in attached communities of the JdFR and whose function was previously unknown. Five of the eleven MAGs had no similarity to other JdFR fluid MAG genomes (JdFRolivine-1, 2, 5, 6, 7; Fig. 3) [15], and the other six were between 76 and 99\% similar to other MAGs from this system (JdFRolivine3, 4, 8-11; Supplementary Table 4). The olivine biofilm MAGs presented herein were previously identified as biofilm organisms colonizing substrates in the JdFR aquifer. These substrates encompass a variety of Fe-bearing igneous rocks and minerals $[1,12]$ and the surface of a nearby steel well head exposed to venting aquifer fluid $[17,46]$. This further supports the notion that these organisms are associated with the sessile, rather than the planktonic, community of the JdFR, and may particularly be associated with Fe-bearing substrates capable of producing $\mathrm{H}_{2}$.

The microbial communities of the eastern flank aquifer of the JdFR are dominated by Firmicutes, Archaea, and other uncultured Bacteria with no close relatives $[1,12,14$, 47]. Clostridia have been found primarily in attached communities of colonized surfaces [1, 12, 17], as have members of the candidate phyla Acetothermia (formerly OP1) and Amenicenantes (formerly OP8) [12, 14, 48, 49]. Some Firmicutes and Acetothermia are capable of using the Wood-Ljungdahl pathway [18, 50, 51]. JdFRolivine- 8 from this community belongs to the Family Peptococcaceae, a relative of Candidatus Desulforudis audaxviator [50] and
Ca. Desulfopertinax cowenii (Fig. 3; Supplementary Table 2) [52]. These organisms are common deep subsurface inhabitants of both the JdFR aquifer and continental aquifers $[12,14,15,50,52]$, and though uncultivated, possess a suite of energy and carbon metabolisms, including the potential to fix carbon via the Wood-Ljungdahl pathway $[50,52]$. The most abundant archaeal lineage in the JdFR aquifer community is Archaeoglobaceae [1, 12, 14, 16, 47]. Members of this lineage can use the acetyl-CoA, or carbonyl branch of the Wood-Ljungdahl pathway [25] and their corresponding enzymes are domain-specific. Methanogenic archaea have been detected in the JdFR aquifer through activity measurements and 16S rRNA gene sequencing $[1,11,13,17]$, but do not appear to be dominant members of this olivine biofilm community.

The co-dominance of Clostridia and Archaeoglobaceae lineages has been described in terrestrial deep subsurface environments such as continental mines and fractures as well as marine aquifers $[1,15,16,50,52-54]$, and we are just beginning to understand their role in cycling carbon and producing energy in the deep crust. Their presence here in this JdFR community indicates there may be a shared hydrogen-based functional role for these microorganisms in deep thermal aquifers. This study also significantly expands the number of marine genomes containing the WoodLjungdahl pathway and suggests that this pathway is more common in these environments than previously known. Since deep thermal aquifers are isolated from the surface where photosynthetic productivity occurs, primary production in these systems is likely dependent on chemosynthesis using the available energy sources from water-rock reactions. The bifunctional Wood-Ljungdahl pathway may be favored over heterotrophy in these types of systems where oxygen and organic matter are low but hydrogen is replete [20].

\section{Wood-Ljungdahl pathway enzymes}

The Wood-Ljungdahl pathway featured prominently in the MAGs from this young, thermal basaltic aquifer, and was present in all but one of the bacterial genomes (Fig. 4). Three of the five bacterial MAGs lacking one step to complete this pathway belong to the order Clostridiales (JdFrolivine-1, 6, and 8), and the other two are classified only as Bacteria (JdFRolivine-3 and 4). The Clostridiales MAGs are missing the carbon-reducing first step in the methyl branch of the Wood-Ljungdahl pathway, which results in the production of formate and is carried out by a formate dehydrogenase enzyme [55]. Fluid MAG JdFR-65 is also missing this enzyme. JdFRolivine- 3 and 4 are also missing a step in this pathway (as are the fluid MAGs JdFR47 and 48; JdFR-46 has no Wood-Ljungdahl pathway), which requires methylene-tetrahydrofolate (methylene- 
THF) reductase; however, this enzyme was previously determined to be 'dispensable' in an analysis of core and pan genomes of acetogens using the Wood-Ljungdahl pathway [56]. It is possible that these organisms contain enzymes that can perform these functions, but they have yet to be identified (Fig. 5c; see Supplementary Materials for details). These organisms are all predicted to be able to use the Wood-Ljungdahl pathway (Fig. 5a) and fix carbon, with putative $f d h A$ genes or alternate pathways outlined here. In addition, we found acs gene clusters, which are markers for the Wood-Ljungdahl pathway in bacteria [18], in all bacterial MAGs (Supplementary Figure 2). These gene clusters included genes coding for enzymes in the Wood-Ljungdahl pathway and those that relate to energy conservation or generation, including ferredoxins, cytochromes, and hydrogenases.

\section{The acetyl-CoA pathway}

The acetyl-CoA pathway was complete in all Archaeoglobaceae MAGs (Fig. 4). The genes in this pathway code for the Archaeal-type carbon-fixing CODH/acetyl-CoA enzymes used in the carbonyl branch of the methanogenic Wood-Ljungdahl pathway [57]. These are analogous to the bacterial CODH/acs system of the acetogenic WoodLjungdahl pathway present in seven bacterial MAGs. Thus, ten of the eleven MAGs obtained from this study have complete acetyl-CoA pathways or the analogous carbonyl branch of the Wood-Ljungdhal pathway that would enable them to fix carbon.

\section{Nitrogen, sulfur, and iron metabolism}

Only JdFRolivine-8 contained a complete pathway for nitrogen fixation (Fig. 4). This MAG is phylogenetically similar to the $\mathrm{Ca}$. Desulforudis and $\mathrm{Ca}$. Desulfopertinax lineages (77-80\%, respectively; Fig. 3). The genome of $\mathrm{Ca}$. Desulforudis audaxviator also contains a nitrogen fixation pathway, but $\mathrm{Ca}$. Desulfopertinax cowenii's genome does not $[50,52]$. Although nitrogen does not appear to be a limiting nutrient based on bulk measures of JdFR aquifer fluids $\left(\left[\mathrm{NH}_{4}^{+}\right]=111 \mu \mathrm{mol} \mathrm{kg}{ }^{-1} \quad\left[\mathrm{NO}_{3}{ }^{-}\right]=0.8 \mu \mathrm{mol} \mathrm{kg}{ }^{-1}\right)$ [28], nitrogen may become limited in the biofilm microniches investigated here.

Sulfate reduction may play a prominent role in energy metabolism in this community. At least four out of the eleven MAGs recovered from the olivine biofilm had complete pathways for dissimilatory sulfate reduction (Fig. 4). This is consistent with the presence of sulfate in the anoxic aquifer fluid at the time of recovery $\left(17.6 \mathrm{mmol} \mathrm{kg}^{-1}\right)[27$, 28 ], and the prediction that the use of sulfate as a terminal electron acceptor is thermodynamically favorable in the JdFR aquifer [58]. Sulfate-reducing lineages have previously been reported from multiple subseafloor microbial observatory studies on the eastern flank of the JdFR, including the location of this study, IODP Hole 1301A [1, 12-14, 59]. Species of Archaeoglobus are known to reduce sulfate either using organic carbon or $\mathrm{H}_{2}$ as initial electron sources [19, 46]. Two of the three archaeal genomes identified from the olivine biofilm in this study (an Archaeoglobus member and another Archaeoglobaceae with $78 \%$ similarity to the JdFR sulfate-reducing isolate $A$. sulfaticallidus) also contain this pathway [46], indicating a metabolic commonality across the microbial community in this environment.

The only iron metabolism predicted to occur in this community is iron reduction by JdFRolivine-10. Iron oxidation could occur in this habitat as olivine contains abundant reduced iron and nitrate is present in the fluids; however, this community of organisms appears to benefit from the oxidation of iron by water, using hydrogen instead to power carbon fixation.

\section{Hydrogenases and other ETAs}

Hydrogenases have been suggested to be important components of early metabolisms on Earth [60], and may have been a precursor to respiratory Complex I and the use of chemiosmosis for energy conservation [61]. They play a key role in hydrogenotrophic metabolisms like the WoodLjungdahl pathway [62], and can facilitate the uptake and oxidation of $\mathrm{H}_{2}$ to $2 \mathrm{H}^{+}$using oxidants such as $\mathrm{O}_{2}, \mathrm{CO}_{2}$, $\mathrm{NO}_{3}{ }^{-}, \mathrm{SO}_{4}{ }^{2-}$, and fumarate [62]. The Wood-Ljungdahl pathway utilizes hydrogenases to provide reducing equivalents for $\mathrm{CO}_{2}$ reduction in both branches, and ETAs such as ferredoxins and cytochromes, couple this pathway to energy conservation [42]. Hydrogenases are also more abundant in $\mathrm{H}_{2}$-rich environments such as serpentinizing systems [63], and the types of hydrogenases present are likely linked to their role in particular redox reactions that depend on specific substrates, the partial pressure of $\mathrm{H}_{2}$, and whether or not the reactions are coupled to the Wood-Ljungdahl pathway [64].

The distribution of hydrogenases and related genes across the olivine-hosted MAGs was variable (Fig. 6). JdFRolivine-7, a likely heterotroph and the only bacterial MAG that did not possess the Wood-Ljungdahl pathway, had few hydrogenase genes, and these were different than in the other MAGs. JdFRolivine-5 and 8 had similar complements of hydrogenases genes, including the ech hydrogenase, which is used by some acetogens for energy conservation by acting as a proton pump [64]. This provides a mechanism for additional ATP generation via proton pumping across the plasma membranes of these cells, allowing for an increased energy yield from acetogenesis; another valuable strategy in low energy environments like deep oceanic crust. All MAGs contained ATPases (data not 
shown), suggesting that energy conservation via the generation of a proton motive force is possible in these organisms. Moorella thermoacetica, an acetogen and close relative of the Clostridial MAGs from this study, also uses the ech complex to conserve energy [64], although the hyd or $n f n$ electron-bifurcating hydrogenases that this organism uses were not present in the olivine MAGs. The hnnCD hydrogenase genes found in the Archaeal genomes code for the $\mathrm{F}_{420}$-reducing hydrogenase (Supplementary Table 4), which is used in the methanogenic Wood-Ljungdahl pathway $[61,62]$. The two 'Bacteria' MAGs had identical sets of hydrogenases, ferredoxins, and cytochrome genes. Both encoded a set of hydrogenase genes, hoxHYU, whose product is a 'hydrogen sensor' that regulates the transcription of other hydrogenases. Both of these 'Bacteria' are evolutionarily distinct from the Clostridia in this study, which may explain why their complement of hydrogenases is unique.

Although JdFRolivine-5 and 8 shared similar hydrogenases, they did not contain similar ferredoxin or cytochrome genes. The JdFRolivine-5 genome was unusual in that it had the greatest number of ferredoxin genes and its cytochromes were most similar to the archaeal gene set. These groups shared both the $\mathrm{ccm}$ and the $s d h$ genes, respiratory membrane proteins responsible for cytochrome $\mathrm{C}$ maturation [65] and the succinate dehydrogenase respiratory complex. Cytochrome $\mathrm{C}$ and succinate dehydrogenase have a role in generating energy using electron transport coupled to proton pumping. Only six MAGs contained the complete succinate dehydrogenase gene set and are able to make all four subunits, and only three of those genomes are able to produce a fully functional cytochrome C.

\section{Similarity of JdFRolivine MAGs to other MAGs from this system}

About half of the olivine biofilm MAGs are dissimilar ( $<75 \%$ similarity) to fluid MAGs (Supplementary Table 4). These divergent MAGs are dominant in the olivine community [12], but are less abundant or absent from the fluid community based on previous community-based studies at these sites [12, 14-16, 47, 59]. Of those JdFRolivine MAGs that are close $(>75 \%)$ relatives of JdFR aquifer fluid MAGs from boreholes U1362A and U1362B [15] (Fig. 3; Supplementary Table 4), two have very high similarity (99\%) with fluid MAGs (JdFRolivine-3 and 9). Of the seven JdFRolivine MAGs identified in this study that contain the Wood-Ljungdahl pathway, six of them group with other JdFR fluid MAGs and five contain the Wood-Ljungdahl pathway (JdFRolivine-1, 2, 5, and 6). All of these group with known or proposed acetogens such as $M$. thermoacetica and $\mathrm{Ca}$. D. audaxviator (Fig. 3), which suggests there is a potentially diverse group of acetogens in the deep biosphere at the Juan de Fuca Ridge.

\section{Olivine community conceptual model}

This olivine community has the genomic potential to grow autotrophically and heterotrophically using energy and carbon substrates originating either from aquifer fluid, water-rock reactions, or fixed carbon of the biofilm. Phosphate, organic and inorganic carbon, dinitrogen, and sulfate are all present in the JdFR aquifer fluid [28] and are potentially utilized by the community (Fig. 7) as evidenced by the presence of complete metabolic pathways for these substrates. Formate and acetate may be produced in the biofilm (Figs. 3 and 4); however, neither of these have been detected in aquifer fluids $(<0.1 \mu \mathrm{M}$; Tina Lin, personal communication) [28]. Key organisms in the community may be using the acetate to power sulfate or iron reduction or for fermentation [19, 43]. Molecular hydrogen is also

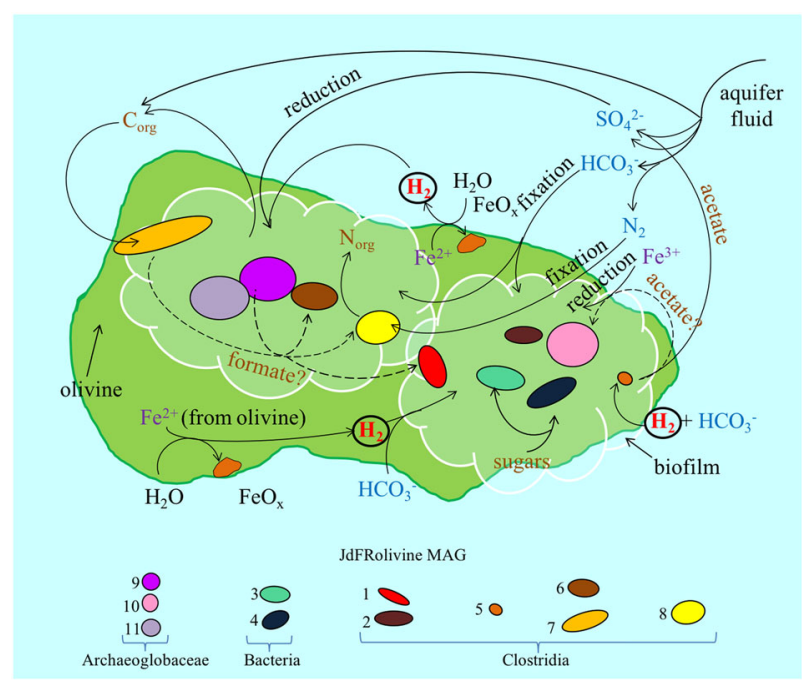

Fig. 7 Olivine community model depicting nutrient cycling and proposed routes of metabolites and substrates. Each oval represents a bacterial (1-8) or archaeal (9-11) cell from the olivine biofilm community. The large green structure is olivine and it contains white cloud shapes that indicate biofilms produced by the community. Colors of MAG ovals correspond to those in Fig. 2 and broad taxonomic groups are indicated below. Water reacting with reduced iron in olivine produces molecular hydrogen and iron oxides, which can be deposited on the surface of olivine as secondary minerals (orange structures on olivine). The molecular hydrogen from this reaction is presumed to help fuel the microbial biofilm through the Wood-Ljungdahl pathway. Nutrients originating from aquifer fluid (blue background) are bicarbonate or $\mathrm{CO}_{2}$, sulfate, nitrogen, and organic carbon. Nutrients produced or consumed by individual cells are drawn with arrows directly to or from the cell. Nutrients going into or out of multiple cells are indicated by arrows to or from the biofilm. Dashed lines are putative routes of production and consumption of nutrients. Solid lines indicate the genomic potential for metabolism of particular substrates. Blue text indicates inorganic nutrients, purple text are iron species, brown text is organic matter, and molecular hydrogen is red 
present in aquifer fluid, and although its concentration is high enough to support hydrogenotrophy $(\sim 2 \mu \mathrm{M})$ [11], additional $\mathrm{H}_{2}$ produced on mineral surfaces could be a major source of energy fueling this microbial community (Fig. 7). The $\mathrm{H}_{2}$, formate, and acetate may be rapidly consumed in a biofilm community and concentrations would, therefore, be low or undetectable in the fluids.

All organisms except for the heterotroph JdFRolivine-7 have hydrogenotrophic carbon fixation pathways. The JdFRolivine-7 genome contains transporters and pathways for degrading a wide variety of organic substrates, but no genomic evidence for carbon fixation. It is, however, genetically capable of rapidly producing large amounts of formate (Fig. 5c), which may be utilized by other microbes whose genomes lack formate dehydrogenase, allowing them another energetic advantage in this energy-limited environment [66]. JdFRolivine-5 is likely the second most abundant organism in this community based on a previous study [12] and appears to rely solely on $\mathrm{H}_{2}$ from water-rock reactions as an energy source. This organism is able to make acetate, which could supplement heterotrophy or be used for iron or sulfate reduction (Fig. 7). The JdFRolivine3 and 4 MAGs can import simple sugars that may be produced in the biofilm, and also use the Wood-Ljungdahl pathway.

\section{Conclusion}

This study provides genomic evidence of a marine subsurface chemosynthetic community that is dependent on $\mathrm{H}_{2}$, presumably released as a result of water reacting with Fe-bearing minerals, and sulfate from the fluids. The Wood-Ljungdahl pathway is the predominant metabolic strategy in this community, which is at odds with the paradigm that the Calvin cycle is the dominant carbon fixation pathway in oceanic crust. This study broadens our understanding of deeper anoxic aquifer communities, which comprise the bulk of oceanic crust, and their interactions with mineral surfaces. Olivine is ubiquitous in oceanic crust and thus is likely to impact microbial community function in both basalts and ultramafic rocks, perhaps even more so in ultramafic crust where olivine comprises up to $50 \%$ of the crust. The Wood-Ljungdahl pathway is an ancient $\mathrm{H}_{2}$-based biosynthetic pathway used by early life on Earth, and having a better understanding of the organisms that utilize this pathway and their strategies for energy conservation may help elucidate its role in the origin and evolution of life.

\section{Data availability}

Raw sequence files and draft genomes are publicly available under the Bioproject Number PRJNA264811 (accession \#s
SDWF00000000, SESU00000000-SESZ00000000, SETA00000000-SETD00000000) on the NCBI website at https://www.ncbi.nlm.nih.gov and at https://figshare.com/a rticles/olivine_contig-65_fa/7252121.

Acknowledgements Metagenome sequencing was made possible by the Deep Carbon Observatory Census of Deep Life supported by the Alfred P. Sloan Foundation and was performed at the Marine Biological Laboratory (Woods Hole, MA, USA). We are grateful for the assistance of Mitch Sogin, Susan Huse, Joseph Vineis, Andrew Voorhis, Sharon Grim, and Hilary Morrison at MBL. Andrew Fisher, C. Geoffrey Wheat, Hans Jannasch, Stefan Sievert, Keir Becker, Mark Nielsen, and the crews of submersible DSRV Alvin and the R/V Atlantis and D/V JOIDES Resolution assisted with flow cell development, deployment, and retrieval. William Rugh contributed to the design of the flow cells. This is a Center for Dark Energy Biosphere Investigations (C-DEBI) contribution.

\section{Compliance with ethical standards}

Conflict of interest The authors declare that they have no conflict of interest.

Publisher's note: Springer Nature remains neutral with regard to jurisdictional claims in published maps and institutional affiliations.

\section{References}

1. Orcutt BN, Bach W, Becker K, Fisher AT, Hentscher M, Toner $\mathrm{BM}$, et al. Colonization of subsurface microbial observatories deployed in young ocean crust. ISME J. 2011;5:692-703.

2. Edwards KJ, Becker K, Colwell F. The deep, dark energy biosphere: intraterrestriallife on earth. Annu Rev Earth Planet Sci. 2012;40:551-68. https://doi.org/10.1146/annurev-earth-042711105500

3. Bach W, Edwards KJ. Iron and sulfide oxidation within the basaltic ocean crust:implications for chemolithoautotrophic microbial biomass production. Geochim Cosmochim Acta. 2003;67:3871-87.

4. Edwards KJ, Bach W, Rogers DR. Geomicrobiology of the ocean crust: a role for chemoautotrophic Fe-bacteria. Biol Bull. 2003;204:180-5.

5. Orcutt BN, Sylvan JB, Rogers DR, Delaney J, Lee RW, Girguis PR. Carbon fixation by basalt-hosted microbial communities. Front Microbiol. 2015;6:1-14.

6. Fisher AT, Urabe T, Klaus A. IODP expedition 301 installs three borehole crustal observatories, prepares for three-dimensional, cross-hole experiments in the northeastern Pacific Ocean. Sci Drill. 2005a;1:6-11. https://doi.org/10.2204/iodp.sd.1.01.2005, 2005.

7. Fisher AT, Wheat CG, Becker K, Davis EE, Jannasch H, Schroeder D, et al. Scientific and technical design and deployment of long-term subseafloor observatories for hydrogeologic and related experiments, IODP Expedition 301, eastern flank of Juan de Fuca Ridge. Proc Integr Ocean Drill Progr. 2005b; 301. https:// doi.org/10.2204/iodp.proc.301.103.2005

8. Wheat CG. Heat flow through a basaltic outcrop on a sedimented young ridge flank. Geochem Geophys Geosyst. 2004;5:Q12006. https://doi.org/10.1029/2004GC000700

9. Mayhew LE, Ellison ET, Mccollom TM, Trainor TP, Templeton AS. Hydrogen generation from low-temperature water-rock reactions. Nat Geosci. 2013;6:478-84. https://doi.org/10.1038/ NGEO1825 
10. Neubeck A, Thanh Duc N, Hk Hellevang, Oze C, Bastviken D, Bacsik $\mathrm{Z}$, et al. Olivine alteration and $\mathrm{H}_{2}$ production in carbonaterich, low temperature aqueous environments. Planet Space Sci. 2014;96:51-61.

11. Lin H-T, Cowen JP, Olson EJ, Lilley MD, Jungbluth SP, Wilson ST, et al. Dissolved hydrogen and methane in the oceanic basaltic biosphere. Earth Planet Sci Lett. 2014;405:62-73.

12. Smith AR, Fisk MR, Thurber AR, Flores GE, Mason OU, Popa R, et al. Deep crustal communities of the Juan de Fuca Ridge are governed by mineralogy. Geomicrobiol J. 2016;34:147-56. https://doi.org/10.1080/01490451.2016.1155001

13. Lever MA, Rouxel O, Alt JC, Shimizu N, Ono S, Coggon RM, et al. Evidence for microbial carbon and sulfur cycling in deeply buried ridge flank basalt. Science. 2013;339:1305-8.

14. Jungbluth SP, Grote J, Lin H-T, Cowen JP, Rappé MS. Microbial diversity within basement fluids of the sediment-buried Juan de Fuca Ridge flank. ISME J. 2013;7:161-72. https://doi.org/10. 1038/ismej.2012.73

15. Jungbluth SP, Amend JP, Rappé MS. Metagenome sequencing and 98 microbial genomes from Juan de Fuca Ridge flank subsurface fluids. Sci Data. 2017;4:170037. https://doi.org/10.1038/ sdata.2017.37

16. Cowen JP, Giovannoni SJ, Kenig F, Johnson HP, Butterfield D, Rappé MS, et al. Fluids from aging ocean crust that support microbial life. Science. 2003;299:120-3. https://doi.org/10.1126/ science. 1075653

17. Nakagawa S, Inagaki F, Suzuki Y, Steinsbu BO, Lever MA, Takai $\mathrm{K}$, et al. Microbial community in black rust exposed to hot ridge flank crustal fluids. Appl Environ Microbiol. 2006;72:6789-99.

18. Pierce E, Xie G, Barabote RD, Saunders E, Han CS, Detter JC, et al. The complete genome sequence of Moorella thermoacetica (f. Clostridium thermoaceticum). Environ Microbiol. 2008;10:2550-73.

19. Klenk H-P, Clayton RA, Tomb J-F, Dodson RJ, Gwinn M, Hickey EK, et al. The complete genome sequence of the hyperthermophilic, sulphate-reducing archaeon Archaeoglobus fulgidus. Nature. 1998;394:6342-49.

20. Nitschke W, Russell MJ. Beating the acetyl coenzyme A-pathway to the origin of life. Philos Trans R Soc Lond B Biol Sci. 2013;368:20120258. https://doi.org/10.1098/rstb.2012.0258

21. Grabarse W, Mahlert F, Duin EC, Goubeaud M, Shima S, Thauer RK, et al. On the mechanism of biological methane formation: structural evidence for conformational changes in methylcoenzyme $\mathrm{M}$ reductase upon substrate binding. J Mol Biol. 2001;309:315-30.

22. Fuchs G. Alternative pathways of carbon dioxide fixation: insights into the early evolution of life? Annu Rev Microbiol. 2011;65:635-58. https://doi.org/10.1146/annurev-micro-090110102801

23. Borrel G, Adam PS, Gribaldo S. Methanogenesis and the WoodLjungdahl pathway: an ancient, versatile, and fragile association. Genome Bio Evol. 2016;8:1706-11. https://doi.org/10.1093/gbe/ evw114

24. Berg IA. Ecological aspects of the distribution of different autotrophic $\mathrm{CO}_{2}$ fixation pathways. AEM . 2011;77:1925-36. https:// doi.org/10.1128/AEM.02473-10

25. Braakman R, Smith E. The emergence and early evolution of biological carbon-fixation. PLoS Comput Biol. 2012;8:e1002455. https://doi.org/10.1371/journal.pcbi.1002455

26. Smith A, Popa R, Fisk M, Nielsen M, Wheat CG, Jannasch HW, et al. In situ enrichment of ocean crust microbes on igneous minerals and glasses using an osmotic flow-through device. Geochem Geophys Geosyst. 2011;12:1-19. https://doi.org/10. 1029/2010GC003424

27. Wheat CG, Jannasch HW, Fisher AT, Becker K, Sharkey J, Hulme S. Subseafloor seawater-basalt-microbe reactions: continuous sampling of borehole fluids in a ridge flank environment. Geochem Geophys Geosyst. 2020;11:1-18.

28. Lin H-T, Cowen JP, Olson EJ, Amend JP, Lilley MD. Inorganic chemistry, gas compositions and dissolved organic carbon in fluids from sedimented young basaltic crust on the Juan de Fuca Ridge flanks. Geochim Cosmochim Acta. 2012;85:213-27.

29. McCarthy MD, Beaupré SR, Walker BD, Voparil I, Guilderson TP, Druffel ER. Chemosynthetic origin of ${ }^{14} \mathrm{C}$-depleted dissolved organic matter in a ridge-flank hydrothermal system. Nat Geosci. 2010;4:32-6.

30. Wang $\mathrm{H}$, Edwards KJ. Bacterial and Archaeal DNA extracted from inoculated experiments: implication for the optimization of DNA extraction from deep-sea basalts. Geomicrobiol J. 2009;26:463-69.

31. Reveillaud J, Reddington E, McDermott J, Algar C, Meyer JL, Sylva $\mathrm{S}$, et al. Subseafloor microbial communities in hydrogenrich vent fluids from hydrothermal systems along the MidCayman Rise. Environ Microbiol. 2016;18:1970-87.

32. Simpson JT, Durbin R. Efficient de novo assembly of large genomes using compressed data structures. Genome Res. 2012;22:549-56.

33. Peng Y, Leung HC, Yiu SM, Chin FYL. IDBA-UD: A de novo assembler for single-cell and metagenomic sequencing data with highly uneven depth. Bioinformatics. 2012;28:1420-28.

34. Laczny CC, Pinel N, Vlassis N, Wilmes P. Alignment-free visualization of metagenomic data by nonlinear dimension reduction. Sci Rep. 2014;4:4516. https://doi.org/10.1038/ srep04516

35. Patil KR, Roune L, McHardy AC. The PhyloPythia web server for taxonomic assignment of metagenome sequences. PLoS One. 2012;7:e38581. https://doi.org/10.1371/journal.pone.0038581

36. Parks DH, Imelfort M, Skennerton CT, Hugenholtz P, Tyson GW. CheckM: assessing the quality of microbial genomes recovered from isolates, single cells, and metagenomes. Genome Res. 2015;25:1043-55.

37. Darling AE, Jospin G, Lowe E, Matsen FA 4th, Bik HM, Eisen JA. PhyloSift: phylogenetic analysis of genomes and metagenomes. PeerJ . 2014;2:e243. https://doi.org/10.7717/peerj.243

38. Hyatt D, Chen GL, Locascio PF, Land ML, Larimer FW, Hauser LJ. Prodigal: prokaryotic gene recognition and translation initiation site identification. BMC Bioinforma. 2010;11:119. https://doi. org/10.1186/1471-2105-11-119

39. Buchfink B, Xie C, Huson DH. Fast and sensitive protein alignment using. Diamond Nat Meth. 2015;12:59-60. https://doi.org/ 10.1038/nmeth.3176

40. Kanehisa M, Sato Y, Morishima K. BlastKOALA and GhostKOALA: KEGG tools for functional characterization of genome and metagenome sequences. J Mol Biol. 2016;428:726-31. https://doi.org/10.1016/j.jmb.2015.11.006

41. Bowers RM, Kyrpides NC, Stepanauskas R, Hamilton-Smith M, Reddy TBK, Schulz F, et al. Minimum information about a single amplified genome (MISAG) and a metagenome-assembled genome (MIMAG) of bacteria and archaea. Nat Biotech. 2017;35:725-31. https://doi.org/10.1038/nbt.3893

42. Ragsdale SW, Pierce E. Acetogenesis and the Wood-Ljungdahl pathway of $\mathrm{CO}_{2}$ fixation. Biochim Biophys Acta - Proteins Proteom. 2008;1784:1873-98.

43. Slobodkina GB, Kolganova TV, Querellou J, BonchOsmolovskaya EA, Slobodkin AI. Geoglobus acetivorans sp. nov., an iron(III)-reducing archaeon from a deep-sea hydrothermal vent. Int J Syst Evol Microbiol. 2009;59(Pt 11):2880-3.

44. McAllister, SM, Moore RM, Gartman A, Luther GW III, Emerson D, Chan CS Marine Fe-oxidizing Zetaproteobacteria: historical, ecological, and genomic perspectives. bioRxivorg 2018;416842. https://doi.org/10.1101/416842. 
45. Clarke TA, Mills PC, Poock SR, Butt JN, Cheesman MR, Cole JA, et al. Escherichia coli Cytochrome c Nitrite Reductase. NrfA Methods Enzymol. 2008;437:63-77. https://doi.org/10.1016/ S0076-6879(07)37004-3

46. Steinsbu BO, Thorseth IH, Nakagawa S, Inagaki F, Lever MA, Engelen B, et al. Archaeoglobus sulfaticallidus sp. nov., a thermophilic and facultatively lithoautotrophic sulfate-reducer isolated from black rust exposed to hot ridge flank crustal fluids. Int J Syst Evol Microbiol. 2010;60(Pt 12):2745-52.

47. Jungbluth SP, Bowers RM, Lin H-T, Cowen JP, Rappé MS. Novel microbial assemblages inhabiting crustal fluids within midocean ridge flank subsurface basalt. ISME J. 2016;10:2033-47. https://doi.org/10.1038/ismej.2015.248

48. Hugenholtz P, Pitulle C, Hershberger KL, Pace NR. Novel division level bacterial diversity in a Yellowstone hot spring. J Bacteriol. 1998;180:366-76.

49. Rinke C, Schwientek P, Sczyrba A, Ivanova NN, Anderson IJ, Cheng J-F, et al. Insights into the phylogeny and coding potential of microbial dark matter. Nature. 2013;499:431-7.

50. Chivian D, Brodie EL, Alm EJ, Culley DE, Dehal PS, DeSantis TZ, et al. Environmental genomics reveals a single-species ecosystem deep within earth. Science. 2008;322:275-8. https://doi. org/10.1126/science. 1155495

51. Takami H, Noguchi H, Takaki Y, Uchiyama I, Toyoda A, Nishi S, et al. A deeply branching thermophilic bacterium with an ancient acetyl-CoA pathway dominates a subsurface ecosystem. PLoS One. 2012. https://doi.org/10.1371/journal.pone.0030559.

52. Jungbluth SP, del Rio TG, Tringe SG, Stepanauskas R, Rappé MS. Genomic comparisons of a bacterial lineage that inhabits both marine and terrestrial deep subsurface systems. Peer J. 2017;5: e3134. https://doi.org/10.7717/peerj.3134

53. Momper L, Jungbluth SP, Lee M, Amend J. Energy and carbon metabolisms in a deep terrestrial fluid microbial community. ISME J. 2017;11:2319-33. https://doi.org/10.1038/ ismej.2017.94

54. Magnabosco C, Ryan K, Lau MC, Kuloyo O, Sherwood Lollar B, Kieft TL, et al. A metagenomic window into carbon metabolism at $3 \mathrm{~km}$ depth in Precambrian continental crust. ISME J. $2015 ; 10: 730-41$.
55. Ragsdale SW. Enzymology of the Woods-Ljungdahl Pathway of Acetogenesis. Ann N Y Acad Sci. 2008;1125:129-36. https://doi. org/10.1196/annals.1419.015

56. Shin J, Song Y, Jeong Y, Cho BK. Analysis of the core genome and pan-genome of autotrophic acetogenic bacteria. Front Microbiol. 2016;7:1531. https://doi.org/10.3389/fmicb.2016.01531

57. Maupin-Furlow JA, Ferry JG. Analysis of the CO dehydrogenase/ acetyl-coenzyme A synthase operon of Methanosarcina thermophila. J Bacteriol. 1996;178:6849-56.

58. Boettger J, Lin H-T, Cowen JP, Hentscher M, Amend JP. Energy yields from chemolithotrophic metabolisms in igneous basement of the Juan de Fuca ridge flank system. Chem Geol. 2013;3378:11-9. https://doi.org/10.1016/j.chemgeo.2012.10.053

59. Robador A, Jungbluth SP, LaRowe DE, Bowers RM, Rappé MS, Amend JP, et al. Activity and phylogenetic diversity of sulfatereducing microorganisms in low-temperature subsurface fluids within the upper oceanic crust. Front Microbiol. 2015. https://doi. org/10.3389/fmicb.2014.00748.

60. Boyd ES, Schut GJ, Adams MWW, Peters JW. Hydrogen metabolism and the evolution of biological respiration. Microbe . 2014;9:361-7.

61. Peters JW, Schut GJ, Boyd ES, Mulder DW, Shepard EM, Broderick $\mathrm{JB}$, et al. [FeFe]- and [NiFe]-hydrogenase diversity, mechanism, and maturation. Biochim Biophys Acta. 2015;1853:1350-69.

62. Vignais PM, Billoud B. Occurrence, classification, and biological function of hydrogenases: an overview. Chem Rev. 2007; 107:4206-72.

63. Brazelton WJ, Nelson B, Schrenk MO. Metagenomic evidence for $\mathrm{H}_{2}$ oxidation and $\mathrm{H}_{2}$ production by serpentinite-hosted subsurface microbial communities. Front Microbiol. 2012;2:268. https://doi. org/10.3389/fmicb.2011.00268

64. Schuchmann K, Müller V. Autotrophy at the thermodynamic limit of life: a model for energy conservation in acetogenic bacteria. Nat Rev Microbiol. 2014;12:809-21.

65. Sanders C, Turkarslan S, Lee DW, Daldal F. Cytochrome c biogenesis: the Ccm system. Trends Microbiol. 2010;18:266-74.

66. Lever MA. Acetogenesis in the energy-starved deep biosphere-a paradox? Front Microbiol. 2012;2:284. https://doi.org/10.3389/ fmicb.2011.00284. 